\section{Serine phosphorylation and proline isomerization in RNAP II CTD control recruitment of Nrd1}

\author{
Karel Kubicek, ${ }^{1,3}$ Hana Cerna, ${ }^{1,3}$ Peter Holub, ${ }^{1}$ \\ Josef Pasulka, ${ }^{1}$ Dominika Hrossova, ${ }^{1}$ Frank Loehr, ${ }^{2}$ \\ Ctirad Hofr, ${ }^{1}$ Stepanka Vanacova, ${ }^{1,4}$ \\ and Richard Stefl ${ }^{1,4}$
}

${ }^{1}$ CEITEC-Central European Institute of Technology, Masaryk University, Brno, 62500, Czech Republic; ${ }^{2}$ Institute of Biophysical Chemistry, Center for Biomolecular Magnetic Resonance, Goethe-University Frankfurt, 60438 Frankfurt am Main, Germany

Recruitment of appropriate RNA processing factors to the site of transcription is controlled by post-translational modifications of the C-terminal domain (CTD) of RNA polymerase II (RNAP II). Here, we report the solution structure of the Ser5 phosphorylated (pSer5) CTD bound to Nrd1. The structure reveals a direct recognition of pSer5 by Nrd1 that requires the cis conformation of the upstream pSer5-Pro6 peptidyl-prolyl bond of the CTD. Mutations at the complex interface diminish binding affinity and impair processing or degradation of noncoding RNAs. These findings underpin the interplay between covalent and noncovalent changes in the CTD structure that constitute the CTD code.

Supplemental material is available for this article.

Received March 26, 2012; revised version accepted July 12, 2012.

The C-terminal domain (CTD) of the largest subunit of RNA polymerase II (RNAP II) consists of multiple tandem repeats of the heptapeptide consensus Tyr1-Ser2Pro3-Thr4-Ser5-Pro6-Ser7 that is conserved from yeast to humans. The CTD is essential and forms a flexible tail of RNAP II. It serves as a binding platform for various cotranscriptional processing factors (Hirose and Manley 2000; Maniatis and Reed 2002; Meinhart et al. 2005). Phosphorylation and dephosphorylation of Ser2, Ser5, and Ser7 create a unique pattern in coordination with the transcription cycle (Komarnitsky et al. 2000; Meinhart et al. 2005; Phatnani and Greenleaf 2006; Kim et al. 2010; Mayer et al. 2010; Tietjen et al. 2010; Bataille et al. 2012). This phosphorylation pattern, often called the CTD code (Buratowski 2003, 2009; Chapman et al. 2008; Egloff and Murphy 2008), controls the recruitment, activation, and

[Keywords: RNA polymerase II; CTD code; phosphorylation; proline isomerization; RNA processing and degradation; NMR spectroscopy; structure] ${ }^{3}$ These authors contributed equally to this work.

${ }^{4}$ Corresponding author

E-mail richard.stefl@ceitec.muni.cz

E-mail vanacova@chemi.muni.cz

Article published online ahead of print. Article and publication date are online at http://www.genesdev.org/cgi/doi/10.1101/gad.192781.112. displacement of various factors involved in transcription and RNAP II transcript processing (Meinhart et al. 2005). It has been proposed that the CTD code is also affected by noncovalent changes in the CTD structure, such as peptidyl-prolyl bond isomerization (Buratowski 2003); however, the structural basis for such tuning of the CTD code and its role in recruitment of RNA processing factors are not yet fully understood. The importance of the CTD isomerization for Ser5 dephosphorylation has recently been demonstrated for the human and insect Ssu72 phosphatases (Xiang et al. 2010; Werner-Allen et al. 2011).

The pSer5 marks occur predominantly in the early elongation phase and are essential in $3^{\prime}$ end processing of short noncoding genes (Komarnitsky et al. 2000; Gudipati et al. 2008; Vasiljeva et al. 2008a). These marks are specifically recognized by Nrd1 and are required for the Nrd1-dependent termination pathway, used at small nuclear/nucleolar RNAs (sn/snoRNAs), cryptic unstable transcripts (CUTs), and other short RNAP II transcripts (Steinmetz et al. 2001; Arigo et al. 2006; Thiebaut et al. 2006; Vasiljeva et al. 2008a). Recent genome-wide studies in yeast demonstrated the co-occurrence of pSer5 and pSer7 marks at some genes in the early elongation phase (Kim et al. 2010; Mayer et al. 2010; Tietjen et al. 2010). In addition to specific phosphorylation, the Nrd1 termination pathway requires the Ess1 (Pin1 in humans) peptidyl-prolyl isomerase (Singh et al. 2009) that specifically isomerizes the pSer5-Pro6 peptidylprolyl bond in the CTD (Gemmill et al. 2005). In yeast, Ess1 stimulates dephosphorylation of pSer5-Pro6 in vivo (Singh et al. 2009), and therefore it has been hypothesized that it regulates the Nrd1 association with the CTD (Singh et al. 2009). To gain insights into the recruitment process of Nrd1 to the $5^{\prime}$ regions of genes, we determined the solution structure of the Saccharomyces cerevisiae Nrd1 CTDinteracting domain (CID) in complex with a CTD peptide phosphorylated at Ser5. The Nrd1 CID structure reveals a conserved CTD-binding site that engages the $\beta$-turn motif of the CTD formed by Ser $2_{b}-$ Pro $3_{b}-$ Thr $4_{b}-$ pSer $5_{b}$ and a site recognizing selectively the upstream $\mathrm{pSer} 5_{\mathrm{a}}$ and the cis conformation of the pSer $5_{\mathrm{a}}-$ Pro $6_{\mathrm{a}}$ peptidyl-prolyl bond of the CTD. Furthermore, we show that the specific recognition of pSer5 CTD by Nrd1 CID is important for the processing and degradation of noncoding RNAs (ncRNAs) in vivo.

\section{Results and Discussion}

\section{Affinity of Nrd1 to the CTD with 'early' phosphorylation marks}

A previous study demonstrated that Nrd1 favors binding to the CTD with "early" pSer5 marks over the CTD with "late" pSer2 marks (Vasiljeva et al. 2008a). To test the effect of the unphosphorylated CTD and the CTD with the "early" pSer7 and pSer5 CTD marks on the affinity to Nrd1, we performed a quantitative solution-binding assay using fluorescence anisotropy (FA) experiments. We found that Nrd1 binds the pSer5 CTD with a significantly stronger affinity compared with the pSer7 CTD or unphosphorylated CTD (Fig. 1A). Nrd1 shows also only a slightly weaker binding to the doubly phosphorylated pSer5/7 CTD than to the pSer5 CTD (Fig. 1A), 
Kubicek et al.

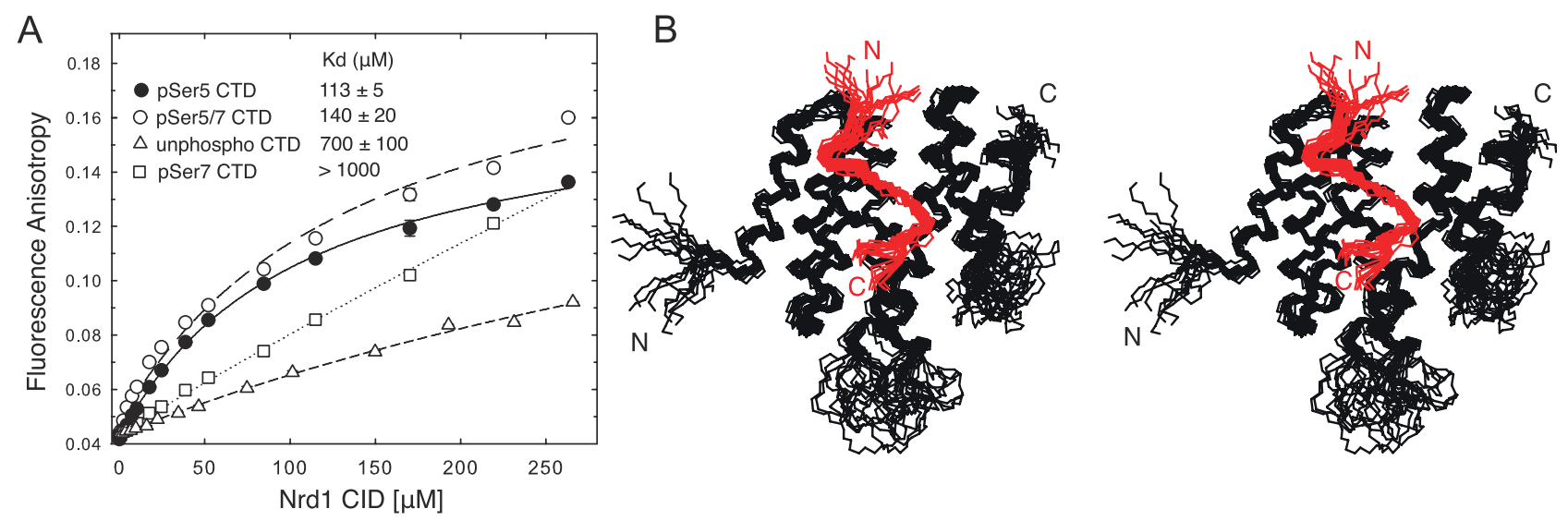

Figure 1. Structure of the Nrd1 CID-pSer5 CTD complex. (A) Equilibrium binding of the Nrd1 CID with differently phosphorylated CTD peptides monitored by FA. Binding isotherms and dissociation constants $\left(K_{\mathrm{d}}\right)$ are shown. $(B)$ Overlay of the 20 lowest-energy structures of the Nrd1 CID-pSer5 CTD complex shown in stereo view. The backbone of the Nrd1 CID and pSer5 CTD is shown in black and red, respectively.

suggesting that the co-occurrence of the pSer5 and pSer7 marks may not impair the recruitment of the Nrdl complex in the early elongation phase.

\section{Structure of Nrd1 CID bound to the phosphorylated CTD}

To understand how the pSer5 CTD is recognized by Nrd1, we determined the solution structure of a reconstituted complex consisting of the CID (residues 1-153) of Nrd1 and a 14-amino-acid peptide, the pSer5 CTD (two repeats of the heptapeptide CTD consensus phosphorylated at Ser5; Tyr1 $1_{\mathrm{a}}-\operatorname{Ser} 2_{\mathrm{a}}-\mathrm{Pro}_{\mathrm{a}}-\mathrm{Thr} 4_{\mathrm{a}}-\mathrm{pSer} 5_{\mathrm{a}}-\mathrm{Pro6}_{\mathrm{a}}-\mathrm{Ser}_{\mathrm{a}}-$

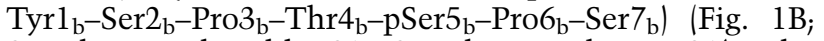
Supplemental Table S1; Supplemental Fig. S1). The ${ }^{1} \mathrm{H},{ }^{13} \mathrm{C}$, and ${ }^{15} \mathrm{~N}$ chemical shift assignments for the bound Nrd1 CID were obtained as described previously (Kubicek et al. 2011). The structure of the Nrd1 CID is formed by eight $\alpha$ helices in a right-handed superhelical arrangement (Fig. 1B) and is virtually identical to the structure of the Nrd1 CID in the free form (Vasiljeva et al. 2008a). The pSer5 CTD peptide contacts helices $\alpha 2, \alpha 4$, and $\alpha 7$ of the Nrd1 CID (Fig. 2A).

\section{Recognition of the phosphorylated CTD by Nrd1}

The CTD peptide adopts a $\beta$-turn conformation at Ser $2_{b^{-}}$ $\mathrm{Pro}_{\mathrm{b}}-\mathrm{Thr}_{\mathrm{b}}-\mathrm{pSer} 5_{\mathrm{b}}$ and docks into a hydrophobic pocket of the Nrd1 CID that is formed by Ile29, Tyr67, Leu127, Ile130, and Met126 using Tyr1 ${ }_{\mathrm{b}}$ and Pro3 $_{\mathrm{b}}$ residues (Fig. 2A,B). The hydroxyl group of Tyr $1_{b}$ forms a hydrogen bond with a conserved aspartate (Asp70) of Nrd1 (Fig. $2 \mathrm{~A}, \mathrm{~B})$. The binding mode of the peptide at the $\beta$-turn conformation resembles other previously determined structures of the CTD bound to CIDs of Pcf11, SCAF8, and Rtt103 (Supplemental Fig. S2; Meinhart and Cramer 2004; Becker et al. 2008; Lunde et al. 2010). However, in contrast to these CID-CTD complexes, Nrd1 binds more residues upstream of the pSer5 CTD via a conserved region at the N-terminal tip of helix $\alpha 2$ (Fig. 2A; Supplemental Fig. S3A). This unique region of Nrd1 is used to specifically recognize pSer $5 \mathrm{a}$ via hydrogen bonding of Ser25 and Arg28 to the phosphate group of pSer5 a (Fig. $2 \mathrm{~A}, \mathrm{~B})$. Another region that is more upstream in the $\alpha 1-\alpha 2$ loop has been previously suggested as the phosphoserine- binding site of Nrd1 based on a sulfate ion that was found in the crystal structure of the free Nrd1 CID (Vasiljeva et al. 2008a). The sulfate ion located $\sim 8 \AA$ away from

A

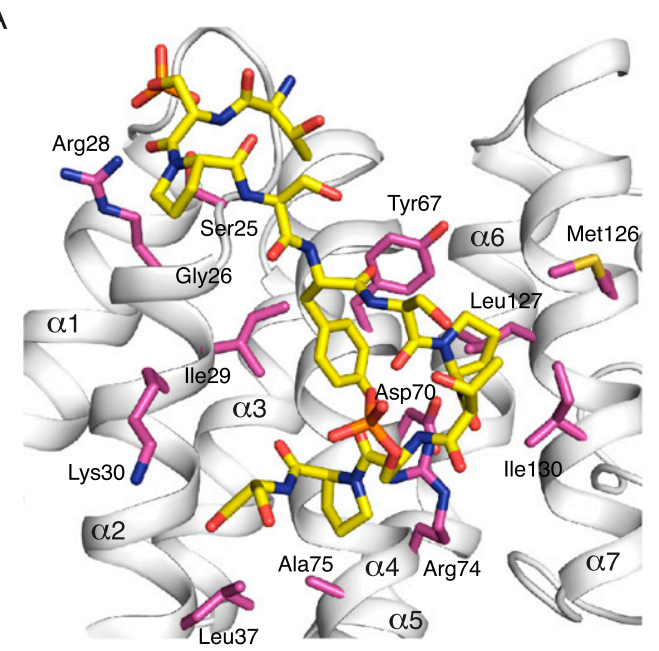

B

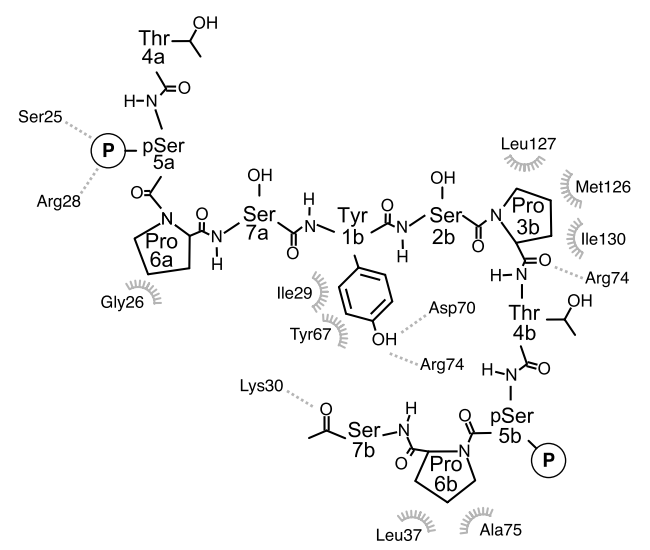

Figure 2. Recognition of the pSer5 CTD by Nrd1. (A) Scheme showing contacts between the Nrdl CID and the CTD peptide. Protein residues that form hydrogen bonds and hydrophobic contacts to the CTD peptide are shown in white sticks. $(B)$ Scheme showing contacts between the Nrd1 CID and the CTD peptide. 
the phosphoserine location identified in our structure is coordinated using nonconserved amino acids. The structure of the Nrd1 CIDpSer5 CTD complex shows that the specific recognition of $\mathrm{pSer}_{\mathrm{a}}$ is facilitated by the cis conformation of the pSer $5_{\mathrm{a}}-\mathrm{Pro6}_{\mathrm{a}}$ peptidyl-prolyl bond. This cis conformation maximizes the intermolecular contacts and prevents the peptide from clashing with the $\alpha 1-\alpha 2$ loop of Nrd1. A conserved G26 in Nrd1 (all other CTD-containing proteins have a bulky and charged residues in this position) (Supplemental Fig. S3B) allows for loading of pSer 5 a into a highly electropositive pocket (Supplemental Fig. S3A). This is the first CID-CTD structure in which a phosphoserineproline bond is observed in the cis conformation and in which a direct recognition of pSer5 is found. Importantly, both features are interconnected and thus required for the efficient binding. A similar conformation of the pSer5 CTD peptide was found in the crystal structure of the Ssu72-pSer5 CTD complex (Supplemental Fig. S4; Xiang et al. 2010; Werner-Allen et al. 2011).

\section{Interaction between Nrd1 and the CTD is} important for cell viability and the processing or degradation of ncRNAs

Specific association of the pSer5 CTD with the Nrd1 CID was further tested in a quantitative in vitro binding assay using FA. We titrated the wild-type and mutant Nrd1 CID against the fluorescently labeled pSer5 CTD. Alanine or aspartate (charge-swapping) substitutions at positions Ser25, Gly26, Arg28, Ile29, and Lys30 significantly decreased the binding affinity with the pSer5 CTD (Fig. 3A; Supplemental Fig. S6, control mutations of nonessential residues). In comparison, the effect of mutants at nonconserved positions Leu20, Lys21, and Ser22 in the region that was previously suggested to bind the phosphoserine (see above) is much smaller (Vasiljeva et al. 2008a). D70R and R74D variants of Nrd1 could not be assayed due to their instability at the high concentrations required for FA measurements. Next, we tested the effect of removal of phosphorylation in the downstream CTD repeat $\left(a t S e r 5_{b}\right)$. We found that the CTD peptide with a single phosphorylation $[\mathrm{pSer} 5(1 \mathrm{P})]$ has the same affinity for Nrd1 as the CTD peptide phosphorylated at both Ser5s (Supplemental Fig. S5). Furthermore, mutations at Pro6 $6_{\mathrm{a}}$ in the CTD peptide $\left(\mathrm{P}_{\mathrm{a}} \mathrm{A}\right.$ CTD and $P 6_{a} R$ CTD) have a larger negative effect on affinity to Nrdl than mutations at Pro6 $6_{b}$ $\left(\mathrm{P}_{\mathrm{b}} \mathrm{A}\right.$ CTD and $\mathrm{P} 6_{\mathrm{b}} \mathrm{R}$ CTD), confirming the requirement of the cis conformation at $\mathrm{pSer} 5_{\mathrm{a}}$ Pro6 a for the binding to Nrd1 (Supplemental Fig. S5). The effect of the $\mathrm{P} 6_{\mathrm{a}} \mathrm{R}$ mutation is larger than for $\mathrm{P}_{\mathrm{a}} \mathrm{A}$, as the bulkier side chain (the side chain at position $\sigma_{a}$ is solvent-exposed) creates more unfavorable interactions with the adjacent side chain of pSer5, decreasing the stability of the cis conformation. This corroborates previous studies that showed that proline-to-alanine mutations do not necessarily alter the cis conformation if
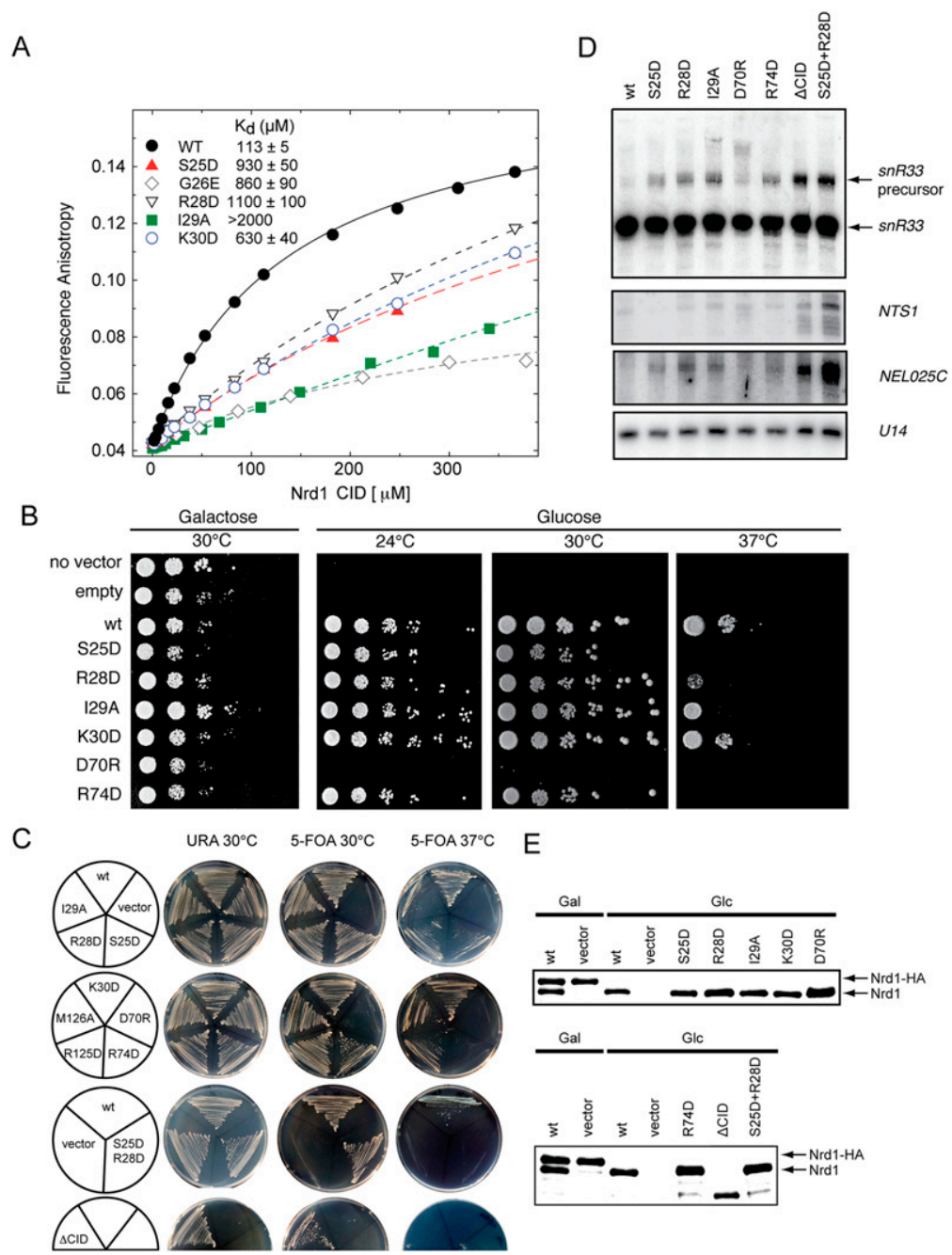

Figure 3. Critical residues of the Nrd1 CID that are required for CTD binding, cell viability, and RNA processing and degradation. (A) Equilibrium binding of the Nrd1 CID mutants with the pSer5 CTD peptide monitored by FA. Binding isotherms and dissociation constants $\left(K_{\mathrm{d}}\right)$ are shown for individual mutants. $(B)$ Phenotypic analysis of the Nrdl CID mutants. The mutants were expressed from pRS415 plasmids in the GAL1::NRD1 strain background. Growth on glucose-containing plates leads to the repression of GAL1-driven wild-type Nrdl and thus shows the functionality of the different Nrdl CID mutants. (C) Phenotypic analysis of the Nrdl CID mutants. The mutants were expressed episomally from $p R S 415$ plasmids in the yeast strain where the endogenous NRD1 was deleted and growth was supplemented with NRD1 on the URA3 plasmid (pRS316). To test the functionality of the different Nrd1 CID mutants, cells were grown on 5-FOA-containing plates for $3 \mathrm{~d}$ at the indicated temperatures. Wild-type NRD1 was used as positive control, empty pRS415 plasmid was used as negative control, and $\mathrm{Nrdl}_{\Delta 1-150}$ was the $\triangle \mathrm{CID}$. (D) snR33 snoRNA processing efficiency and stability of NTS1 and NEL025C CUTs analyzed by Northern blot analysis. Mature $U 14$ snoRNA represents a loading control. Total RNA was purified from cells expressing wild-type NRD1 or the indicated mutants grown in glucosecontaining medium. $(E)$ Western blot analysis of expression levels of the wild-type and mutant Nrd1 originating from pRS415 (faster-migrating band) in the yeast strain where the endogenous NRD1 is under the galactose promoter. Protein extracts were prepared from the original GAL1::NRD1 strain transformed with plasmids carrying wild-type and mutant NRD1 grown in either galactose-containing medium (Gal) or glucose-containing medium (Glc). (Top band) The genomic NRD1 copy contains a fusion HA tag, resulting in slower gel migration. Proteins were detected using specific antibodies against Nrdlp. Vectors with no insertion (vector) or containing the wild-type NRD1 were used as negative and positive controls, respectively.

it is enforced by the structural context (Mayr et al. 1994; Xiong et al. 2000). Altogether, the FA data strongly support the phosphorylation-specific recognition ob- 
served in the structure of the Nrd1-pSer5 CTD complex and that the interaction relies on the presence of the invariant basic residues in the CID domain (Supplemental Fig. S3A).

To determine the importance of these individual residues for Nrd1 function in vivo, we monitored cell viability and ncRNA processing/stability in single-amino-acid mutants (Fig. 3B-D). The Nrd1 strain lacking the CID $(\mathrm{Nrd} 1 \Delta 1-150)$ was used as a reference for the CID-related function. Deletion of the CID is not lethal (Vasiljeva et al. 2008a); however, we observed that deletion of the CID led to inviability at $37^{\circ} \mathrm{C}$ (Fig. 3C). Similarly, to a lesser extent, a temperature-sensitive (ts) growth defect was observed in mutants of Ser25, Arg28, Ile29, and Arg74 (Fig. 3B,C). The double mutant in the residues contacting the phosphorylated serine (Ser25+Arg28) exhibited the same growth phenotype as $\Delta$ CID Nrd1 (Fig. 3C). Nrd1 CID deletion causes an accumulation of $s n R 33$ precursors in vivo (Vasiljeva et al. 2008a). We observed that point mutants with the ts growth phenotype showed snoRNA processing and CUT degradation defects demonstrated by an accumulation of pre-snR33 snoRNA and NEL025c and NTS1 CUTs, respectively (Fig. 3D,E; Supplemental Fig. S7). None of the Nrd1 CID mutants tested displayed transcription termination defects that would be represented by readthrough product accumulation. Importantly, the Ser25+Arg28 double mutant showed processing and degradation defects comparable with those of the mutant lacking the entire Nrd1 CID. Taken together, these data demonstrate that specific recognition of the pSer5 CTD by the Nrd1 CID is important for the processing and degradation of ncRNAs in vivo.

The Nrd1 complex associates with the exosome and the TRAMP complex (Vasiljeva and Buratowski 2006). Based on our data, it is tempting to speculate that the Nrd1 CID mediates interaction with this processing and degradation apparatus. As the Nrd1 truncation lacking CID ( $\Delta 39-169)$ has no effect on the exosome copurification (demonstrated for Rrp6) (Vasiljeva and Buratowski 2006), it is likely that other RNA processing and degradation auxiliary factors, such as the TRAMP complex (LaCava et al. 2005; Vanacova et al. 2005), are recruited through the Nrd1 CID.

Previous chromatin immunoprecipitation (ChIP) experiments showed that Ess1 promotes the release of Nrd1 from terminator regions (Singh et al. 2009). This observation has been attributed to the indirect effect of Ess1 in which it stimulates dephosphorylation by Ssu72 (Singh et al. 2009). Ssu72 targets specifically the cis conformation of the peptidyl-prolyl bond of the pSer-Pro-containing peptides (Xiang et al. 2010; Werner-Allen et al. 2011). Here we suggest that Ess1 can also directly regulate the association of Nrd1 with the RNA Pol II CTD, as it specifically recognizes the pSer5-Pro6 CTD in the cis conformation, indicating that Ess 1 may play a dual role in regulating the Nrd1 pathway. A detailed understanding of this mechanism will require further studies, but it is an exciting possibility, particularly in light of recent observations that suggested that Ssu72 may be a less "conformation-specific" phosphatase (acting also on the pSer7-Tyr1 CTD peptide that is unlikely to exist in the cis conformation) than previously expected (Bataille et al. 2012; Zhang et al. 2012).

\section{Conclusions}

The structure of Nrd1 CID-pSer5 CTD presented here reveals that the CTD recognition by Nrd1 requires both phosphorylation and isomerization of the RNAPII CTD.
This suggests that the coupling of covalent and noncovalent changes in the CTD structure regulated by kinases/ phosphatases and isomerases is crucial for the dynamical process of recruitment and displacement of appropriate processing factors during the transcriptional cycle. In addition, we show that specific recognition of the pSer5 CTD by the Nrd1 CID is important for the processing and degradation of ncRNAs in vivo, suggesting that these events occur cotranscriptionally.

\section{Materials and methods}

\section{Protein expression and mutagenesis}

The DNA encoding the Saccharomyces cerevisiae Nrd1 CID domain (residues 1-153) was amplified and cloned into a pET22b expression vector (Novagen) via NdeI and XhoI restriction sites. Details on cloning, expression, and purification of the Nrd1 CID construct have been described previously (Kubicek et al. 2011). Protein mutants were designed on the basis of the NMR structure of the Nrd1-pSer5 CTD complex and were prepared using the QuikChange site-directed mutagenesis kit (Stratagene).

\section{The CTD of RNAP II}

It has been established previously that the CTD mimic consisting of two repeats of the CTD canonical heptad yields the same binding affinity to Nrd1 $\mathrm{CID}$ as the CTD mimic of four repeats (Vasiljeva et al. 2008a). Thus, we used a 14-amino-acid peptide, the pSer5 CTD (two repeats of the heptapeptide CTD consensus phosphorylated at two Ser5s; Tyr1 $1_{\mathrm{a}}-$ Ser2 $2_{\mathrm{a}}-\operatorname{Pro} 3_{\mathrm{a}}-\mathrm{Thr} 4_{\mathrm{a}}-$

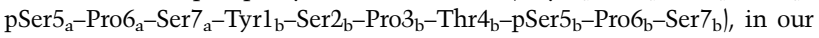
study to mimic the CTD phosphorylated at Ser5. Similarly, the unphosphorylated CTD, the pSer7 CTD, and the doubly phosphorylated pSer5/7 CTD were used. The peptides were purchased from Clonestar Peptide Services.

\section{$N M R$}

All NMR spectra for the backbone and side chain assignments of $2.0 \mathrm{mM}$ uniformly ${ }^{15} \mathrm{~N},{ }^{13} \mathrm{C}$-labeled Nrd1 CID in $50 \mathrm{mM}$ sodium phosphate buffer (pH 8.0), $100 \mathrm{mM} \mathrm{NaCl}$, and $10 \mathrm{mM} \beta$-mercaptoethanol $\left(90 \% \mathrm{H}_{2} \mathrm{O} / 10 \%\right.$ $\mathrm{D}_{2} \mathrm{O}$ ) were recorded on Bruker AVANCE 600- and 950- $\mathrm{MHz}$ spectrometers equipped with a cryoprobe at a sample temperature of $20^{\circ} \mathrm{C}$. The spectra were processed using an NMRPipe package (Delaglio et al. 1995), and the protein resonances were assigned manually using Sparky software (T.G. Goddard and D.G. Kellner, University of California at San Francisco). The ${ }^{1} \mathrm{H},{ }^{13} \mathrm{C}$, and ${ }^{15} \mathrm{~N}$ chemical shifts of the bound form of the Nrd1 CID were assigned as described elsewhere (Kubicek et al. 2011). All distance constraints were derived from the three-dimensional $(3 \mathrm{D}){ }^{15} \mathrm{~N}$ - and ${ }^{13} \mathrm{C}$-separated NOESYs and two-dimensional (2D) ${ }^{1} \mathrm{H}-{ }^{1} \mathrm{H}$ NOESY (with a mixing time of $80 \mathrm{msec}$ ) collected on a $950-\mathrm{MHz}$ spectrometer. Intermolecular distance constraints were obtained from the $3 \mathrm{D} \mathrm{F}_{1}{ }^{13} \mathrm{C} /{ }^{15} \mathrm{~N}$-filtered NOESY- $\left[{ }^{13} \mathrm{C},{ }^{1} \mathrm{H}\right]-\mathrm{HSQC}$ experiment (Zwahlen et al. 1997; Peterson et al. 2004), with a mixing time of $150 \mathrm{msec}$ on a $950-\mathrm{MHz}$ spectrometer. Intramolecular distance constraints of the bound CTD peptide (unlabeled) were derived from a $2 \mathrm{D} \mathrm{F}_{1}, \mathrm{~F}_{2^{-}}{ }^{13} \mathrm{C} /{ }^{15} \mathrm{~N}$-filtered $\left[{ }^{1} \mathrm{H},{ }^{1} \mathrm{H}\right]$-NOESY $\left(\tau_{\mathrm{m}}=150\right.$ msec) (Zwahlen et al. 1997; Peterson et al. 2004). The NOEs were semiquantitatively classified based on their intensities in the 2D and 3D NOESY spectra.

\section{Structure calculations}

The preliminary structure determinations of the Nrd1-pSer5 CTD complex were performed with the automated NOE assignment module implemented in the CYANA program (Guntert 2004). In the next step, CYANA-generated restraints along with manually assigned protein-CTD intermolecular restraints were used for further refinement of the preliminary structures with AMBER 10.0 software (Case et al. 2005). These calculations used a modified version (AMBER ff99SB) of the force field described by Cornell et al. (1995) using a protocol described previously (Stefl et al. 2010, Hobor et al. 2011). From 40 refined structures, the 20 conformers with the lowest AMBER energy were selected to form the final ensemble of structures. Molecular graphics were generated using MOLMOL (Koradi et al. 1996) and PyMOL (http://www.pymol.org). The 
atomic coordinates and restraints for the Nrd1 CID-pSer5 CTD complex have been deposited in the Protein Data Bank under ID code 2 lo6.

$F A$

The equilibrium binding of the Nrd1 CID to the differently phosphorylated CTD was analyzed by FA. The CTD peptides were N-terminally labeled with the 5,6-carboxyfluorescein (FAM). The measurements were conducted on a FluoroMax-4 spectrofluorometer (Horiba Jobin-Yvon). The instrument was equipped with a thermostatted cell holder with a Neslab RTE7 water bath (Thermo Scientific). Samples were excited with vertically polarized light at $477 \mathrm{~nm}$, and both vertical and horizontal emissions were recorded at $525 \mathrm{~nm}$. All measurements were conducted at $10^{\circ} \mathrm{C}$ in $50 \mathrm{mM}$ phosphate buffer $(\mathrm{pH} 8.0)$ containing 100 $\mathrm{mM} \mathrm{NaCl}$ and $10 \mathrm{mM} \beta$-mercaptoethanol. Each data point is an average of five measurements. The experimental binding isotherms were analyzed by nonlinear least-squares regression in SigmaPlot 11 software (Systat Software) using a single-site binding model according to Heyduk and Lee (1990).

\section{Construction of yeast plasmids}

The $p R S 415$ plasmid (CEN, LEU2) with insertion of the wild-type NRD1 gene surrounded by the NRD1 promoter and terminator (Vasiljeva et al. 2008a) was used as a template for QuikChange site-directed mutagenesis (Stratagene). See Supplemental Table S2 for primer sequences and Supplemental Table S3 for constructs generated in this study. The NRD1 $\triangle C I D$ region was amplified as follows: Fragment 1: $-340 \mathrm{nt}$ up to $+6 \mathrm{nt}$ of NRD1 with SVO F71 and SVO F72; Fragment 2: $+453 \mathrm{nt}$ up to TAA +300 nt from the $3^{\prime}$ untranslated region (UTR) with SVO F73 and SVO F74 primers. The two resulting PCR products were ligated together and inserted into the above-mentioned $p R S 415$-based construct.

\section{Yeast cultures and manipulation}

Yeast were cultured under standard conditions in media with selective markers corresponding to particular strains and vectors. Yeast transformations were performed by the lithium acetate method.

\section{Yeast growth test analysis}

W303 (GAL1::NRD1)-derived strains (Supplemental Table S4) carrying appropriate mutant NRD1 plasmids were grown in SD-LEU-HIS $+2 \%$ galactose at $30^{\circ} \mathrm{C}$ to an O.D. of 1.0. The cultures were serially diluted by a factor of 10 and spotted onto SD-LEU-HIS medium containing $2 \%$ glucose to repress the expression of the endogenous NRD1 or control medium (SDHIS $+2 \%$ galactose). Plates were incubated at $25^{\circ} \mathrm{C}, 30^{\circ} \mathrm{C}$, and $37^{\circ} \mathrm{C}$. EJS101-9d-derived strains (Supplemental Table S4) were grown for $3 \mathrm{~d}$ on SC-LEU plates, then spread on SC-LEU plates with or without 5-FOA and incubated at $25^{\circ} \mathrm{C}, 30^{\circ} \mathrm{C}$, and $37^{\circ} \mathrm{C}$.

\section{Whole-cell protein extract preparation for Western} blot analysis

Protein extracts were prepared from cultures grown on either galactose- or glucose-containing medium to an O.D. of 1.0. Five milliliters of culture was harvested and lyzed by $1.85 \mathrm{M} \mathrm{NaOH}$ for $15 \mathrm{~min}$ on ice, and proteins were subsequently precipitated with ice-cold trichloroacetic acid. Pellets were resuspended in 5\% SDS and $8 \mathrm{M}$ urea buffer prior to SDS-PAGE analysis. Proteins were resolved on a $12 \%$ SDS-PAGE gel, transferred to a nitrocellulose membrane by a semidry electroblotter (Bio-Rad), and probed for the presence of Nrdlp with the anti-Nrd1 sera kindly provided by David Brow (Steinmetz and Brow 1998).

\section{RNA isolation and analysis}

For RNA analysis, cells were inoculated to an O.D. of 0.1 in glucose- or galactose-containing SD medium and grown for $16 \mathrm{~h}$ at $30^{\circ} \mathrm{C}$. RNA was isolated by hot phenol extraction and stored at $-80^{\circ} \mathrm{C}$. Five micrograms of total RNA was denatured in $25 \%$ formamide, separated on an $8 \%$ denaturing (8 M urea) polyacrylamide gel, and transferred to nylon membrane using semidry electro-transfer. RNA was cross-linked to the membrane by UV light $\left(120 \mathrm{~mJ} / \mathrm{cm}^{2}\right)$ and hybridized with a probe in Ultra-Hyb buffer (Ambion) according to the manufacturer's instructions.

\section{Preparation of DNA probes for Northern blot analysis}

The DNA probe for $s n R 33$ was amplified from S. cerevisiae S288C genomic DNA with primers Forward, 5'-CGGAACGGTACATAAGAA TAGAAGAG-3', and Reverse, 5'-TAAAGAAAACGATAAGAACTAA CCTC-3'. The NTS1 probe 1 was prepared according to Vasiljeva et al. (2008b), by using primers Forward, 5 '-TGAGTGCTTGTATAAGTTTA GAGAATTGA-3', and Reverse, 5'-TTAATACTTTCCTCTTCGTCTTTT TCTAC-3'. The NELO25c probe was amplified with primers Forward, 5'-CCTGTTGACATTGCAGACAA-3', and Reverse, 5'-GCAAAGATCTG TATGAAAGG- ${ }^{\prime}$. The resulting PCR products were used as templates for random primed labeling using $\left[\alpha-{ }^{32} \mathrm{P}\right] \mathrm{dATP}$ and the commercial kit (Roche). To detect U14 snoRNA, the oligonucleotide 5'-TCACTCAGACATCC TAGG-3' was 5'-phosphate-labeled by T4 polynucleotide kinase (New England Biolabs) and $\left[\gamma_{-}{ }^{32} \mathrm{P}\right] \mathrm{ATP}$.

\section{Acknowledgments}

We thank Anton Meinhart for helpful advice. We also thank Domenico Libri and David Brow for yeast strains, constructs, and antibodies. This work was supported by the project "CEITEC-Central European Institute of Technology" (CZ.1.05/1.1.00/02.0068) from the European Regional Development Fund, Czech Science Foundation (P305/12/G034; K.K. was supported by P305/10/1490, D.H. was supported by P305/11/1095, and C.H. was supported by P205/12/0550), Wellcome Trust 084316/Z/07/Z, and EMBO Installation Grant 1642. The NOESY spectra were obtained at the BMRZ NMR facility supported by the EU-NMR program (RII3-026145). P.H. is in receipt of the Brno City Municipality Scholarship for Talented PhD Students.

\section{References}

Arigo JT, Eyler DE, Carroll KL, Corden JL. 2006. Termination of cryptic unstable transcripts is directed by yeast RNA-binding proteins Nrd1 and Nab3. Mol Cell 23: 841-851.

Bataille AR, Jeronimo C, Jacques PE, Laramee L, Fortin ME, Forest A, Bergeron M, Hanes SD, Robert F. 2012. A universal RNA polymerase II CTD cycle is orchestrated by complex interplays between kinase, phosphatase, and isomerase enzymes along genes. Mol Cell 45: 158-170.

Becker R, Loll B, Meinhart A. 2008. Snapshots of the RNA processing factor SCAF8 bound to different phosphorylated forms of the carboxyl-terminal domain of RNA polymerase II. I Biol Chem 283: 22659-22669.

Buratowski S. 2003. The CTD code. Nat Struct Biol 10: 679-680.

Buratowski S. 2009. Progression through the RNA polymerase II CTD cycle. Mol Cell 36: 541-546.

Case DA, Cheatham TE III, Darden T, Gohlke H, Luo R, Merz KM Jr, Onufriev A, Simmerling C, Wang B, Woods RJ. 2005. The Amber biomolecular simulation programs. J Comput Chem 26: 1668-1688.

Chapman RD, Heidemann M, Hintermair C, Eick D. 2008. Molecular evolution of the RNA polymerase II CTD. Trends Genet 24: 289-296.

Cornell WD, Cieplak P, Bayly CI, Gould IR, Merz KM, Ferguson DM, Spellmeyer DC, Fox T, Caldwell JW, Kollman PA. 1995. A 2nd generation force-field for the simulation of proteins, nucleic-acids, and organic-molecules. I Am Chem Soc 117: 5179-5197.

Delaglio F, Grzesiek S, Vuister GW, Zhu G, Pfeifer J, Bax A. 1995. NMRPipe: A multidimensional spectral processing system based on UNIX pipes. I Biol NMR 6: 277-293.

Egloff S, Murphy S. 2008. Cracking the RNA polymerase II CTD code. Trends Genet 24: 280-288.

Gemmill TR, Wu X, Hanes SD. 2005. Vanishingly low levels of Ess1 prolyl-isomerase activity are sufficient for growth in Saccharomyces cerevisiae. J Biol Chem 280: 15510-15517.

Gudipati RK, Villa T, Boulay J, Libri D. 2008. Phosphorylation of the RNA polymerase II C-terminal domain dictates transcription termination choice. Nat Struct Mol Biol 15: 786-794. 
Guntert P. 2004. Automated NMR structure calculation with CYANA. Methods Mol Biol 278: 353-378.

Heyduk T, Lee JC. 1990. Application of fluorescence energy transfer and polarization to monitor Escherichia coli cAMP receptor protein and lac promoter interaction. Proc Natl Acad Sci 87: 1744-1748.

Hirose Y, Manley JL. 2000. RNA polymerase II and the integration of nuclear events. Genes Dev 14: 1415-1429.

Hobor F, Pergoli R, Kubicek K, Hrossova D, Bacikova V, Zimmermann M, Pasulka J, Hofr C, Vanacova S, Stefl R. 2011. Recognition of transcription termination signal by the nuclear polyadenylated RNA-binding (NAB) 3 protein. I Biol Chem 286: 3645-3657.

Kim H, Erickson B, Luo W, Seward D, Graber JH, Pollock DD, Megee PC, Bentley DL. 2010. Gene-specific RNA polymerase II phosphorylation and the CTD code. Nat Struct Mol Biol 17: 1279-1286.

Komarnitsky P, Cho EJ, Buratowski S. 2000. Different phosphorylated forms of RNA polymerase II and associated mRNA processing factors during transcription. Genes Dev 14: 2452-2460.

Koradi R, Billeter M, Wuthrich K. 1996. MOLMOL: A program for display and analysis of macromolecular structures. J Mol Graph 14: 51-55.

Kubicek K, Pasulka J, Cerna H, Lohr F, Stefl R. 2011. ${ }^{1} \mathrm{H},{ }^{13} \mathrm{C}$, and ${ }^{15} \mathrm{~N}$ resonance assignments for the CTD-interacting domain of $\mathrm{Nrd} 1$ bound to Ser5-phosphorylated CTD of RNA polymerase II. Biomol NMR Assign 5: 203-205.

LaCava J, Houseley J, Saveanu C, Petfalski E, Thompson E, Jacquier A, Tollervey D. 2005. RNA degradation by the exosome is promoted by a nuclear polyadenylation complex. Cell 121: 713-724.

Lunde BM, Reichow SL, Kim M, Suh H, Leeper TC, Yang F, Mutschler H, Buratowski S, Meinhart A, Varani G. 2010. Cooperative interaction of transcription termination factors with the RNA polymerase II C-terminal domain. Nat Struct Mol Biol 17: 1195-1201.

Maniatis T, Reed R. 2002. An extensive network of coupling among gene expression machines. Nature 416: 499-506.

Mayer A, Lidschreiber M, Siebert M, Leike K, Soding J, Cramer P. 2010. Uniform transitions of the general RNA polymerase II transcription complex. Nat Struct Mol Biol 17: 1272-1278.

Mayr LM, Willbold D, Rösch P, Schmid FX. 1994. Generation of a nonprolyl cis peptide bond in ribonuclease T1. J Mol Biol 240: 288-293.

Meinhart A, Cramer P. 2004. Recognition of RNA polymerase II carboxy-terminal domain by 3 '-RNA-processing factors. Nature 430: $223-226$.

Meinhart A, Kamenski T, Hoeppner S, Baumli S, Cramer P. 2005. A structural perspective of CTD function. Genes Dev 19: 1401-1415.

Peterson RD, Theimer CA, Wu H, Feigon J. 2004. New applications of 2D filtered/edited NOESY for assignment and structure elucidation of RNA and RNA-protein complexes. I Biol NMR 28: 59-67.

Phatnani HP, Greenleaf AL. 2006. Phosphorylation and functions of the RNA polymerase II CTD. Genes Dev 20: 2922-2936.

Singh N, Ma Z, Gemmill T, Wu X, Defiglio H, Rossettini A, Rabeler C, Beane O, Morse RH, Palumbo MJ, et al. 2009. The Ess1 prolyl isomerase is required for transcription termination of small noncoding RNAs via the Nrd1 pathway. Mol Cell 36: 255-266.

Stefl R, Oberstrass FC, Hood JL, Jourdan M, Zimmermann M, Skrisovska L, Maris C, Peng L, Hofr C, Emeson RB, et al. 2010. The solution structure of the ADAR2 dsRBM-RNA complex reveals a sequencespecific readout of the minor groove. Cell 143: 225-237.

Steinmetz EJ, Brow DA. 1998. Control of pre-mRNA accumulation by the essential yeast protein Nrd1 requires high-affinity transcript binding and a domain implicated in RNA polymerase II association. Proc Natl Acad Sci 95: 6699-6704.

Steinmetz EJ, Conrad NK, Brow DA, Corden JL. 2001. RNA-binding protein Nrd1 directs poly(A)-independent 3 '-end formation of RNA polymerase II transcripts. Nature 413: 327-331.

Thiebaut M, Kisseleva-Romanova E, Rougemaille M, Boulay J, Libri D. 2006. Transcription termination and nuclear degradation of cryptic unstable transcripts: A role for the nrd1-nab3 pathway in genome surveillance. Mol Cell 23: 853-864.

Tietjen JR, Zhang DW, Rodriguez-Molina JB, White BE, Akhtar MS, Heidemann M, Li X, Chapman RD, Shokat K, Keles S, et al. 2010. Chemical-genomic dissection of the CTD code. Nat Struct Mol Biol 17: 1154-1161.

Vanacova S, Wolf J, Martin G, Blank D, Dettwiler S, Friedlein A, Langen H, Keith G, Keller W. 2005. A new yeast poly(A) polymerase complex involved in RNA quality control. PLoS Biol 3: e189. doi: 10.1371/ journal.pbio.0030189.

Vasiljeva L, Buratowski S. 2006. Nrd1 interacts with the nuclear exosome for $3^{\prime}$ processing of RNA polymerase II transcripts. Mol Cell 21: 239-248.

Vasiljeva L, Kim M, Mutschler H, Buratowski S, Meinhart A. 2008a. The Nrd1-Nab3-Sen1 termination complex interacts with the Ser5-phosphorylated RNA polymerase II C-terminal domain. Nat Struct Mol Biol 15: 795-804.

Vasiljeva L, Kim M, Terzi N, Soares LM, Buratowski S. 2008b. Transcription termination and RNA degradation contribute to silencing of RNA polymerase II transcription within heterochromatin. Mol Cell 29: 313-323.

Werner-Allen JW, Lee CJ, Liu P, Nicely NI, Wang S, Greenleaf AL, Zhou P. 2011. Cis-proline-mediated Ser $(\mathrm{P}) 5$ dephosphorylation by the RNA polymerase II C-terminal domain phosphatase Ssu72. I Biol Chem 286: $5717-5726$.

Xiang K, Nagaike T, Xiang S, Kilic T, Behav MM, Manley JL, Tong L. 2010. Crystal structure of the human symplekin-Ssu72-CTD phosphopeptide complex. Nature 467: 729-733.

Xiong Y, Juminaga D, Swapna GV, Wedemeyer WJ, Scheraga HA, Montelione GT. 2000. Solution NMR evidence for a cis Tyr-Ala peptide group in the structure of [Pro93Ala] bovine pancreatic ribonuclease A. Protein Sci 9: 421-426.

Zhang DW, Mosley AL, Ramisetty SR, Rodríguez-Molina JB, Washburn MP, Ansari AZ. 2012. Ssu72 phosphatase-dependent erasure of phospho-Ser7 marks on the RNA polymerase II C-terminal domain is essential for viability and transcription termination. I Biol Chem 287: 8541-8551.

Zwahlen C, Legault P, Vincent SJF, Greenblatt J, Konrat R, Kay LE. 1997. Methods for measurement of intermolecular NOEs by multinuclear NMR spectroscopy: Application to a bacteriophage $\lambda$ N-peptide/boxB RNA complex. I Am Chem Soc 119: 6711-6721. 


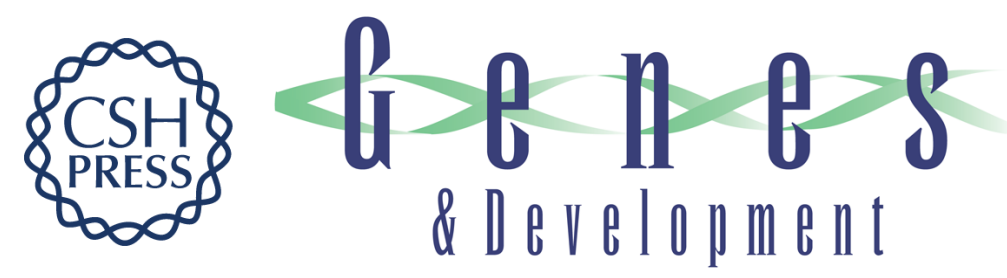

\section{Serine phosphorylation and proline isomerization in RNAP II CTD control recruitment of Nrd1}

Karel Kubicek, Hana Cerna, Peter Holub, et al.

Genes Dev. 2012, 26: originally published online August 14, 2012

Access the most recent version at doi:10.1101/gad.192781.112

\section{Supplemental http://genesdev.cshlp.org/content/suppl/2012/08/09/gad.192781.112.DC1 Material}

References This article cites 44 articles, 11 of which can be accessed free at: http://genesdev.cshlp.org/content/26/17/1891.full.html\#ref-list-1

\section{License}

Email Alerting

Receive free email alerts when new articles cite this article - sign up in the box at the top Service 